\title{
Paediatric nurse training activity in South Africa: A short report
}

\author{
U Ugochukwu, ${ }^{1}$ BSc, MPH; N North, ${ }^{2}$ BA Hons, MSc(Med) Paeds, RGN; \\ S Sieberhagen, ${ }^{2}$ BA, BA Hons (App Ling); BA Hons (Psych); MA (Psych); M Shung-King, ${ }^{1}$ MB ChB, DPhil (Oxon) \\ ${ }^{1}$ Health Policy and Systems Division, School of Public Health and Family Medicine, University of Cape Town, South Africa \\ ${ }^{2}$ Department of Paediatrics and Child Health, Faculty of Health Sciences, University of Cape Town, South Africa
}

Corresponding author: M Shung-King (maylene.shungking@uct.ac.za)

\begin{abstract}
There is widespread concern regarding the size and capacity of the paediatric nursing workforce, which is an important contributor to improved health outcomes for South Africa's (SA) children. As reliable information on the size of the paediatric nursing workforce and associated training activity was not readily available, a small, exploratory study was conducted to ascertain the extent of paediatric nursing training outputs. Data from a survey of training providers were supplemented with records from a forum for paediatric nursing educators, which suggested that an estimated 153 paediatric nurses are produced in SA annually, contrary to the modest numbers suggested by official sources. Additional analysis of national registry figures suggests that the number is increasing. This holds promise of a growing paediatric nursing workforce, which could be harnessed to improve paediatric healthcare. Accurate data can assist in future planning for and training of the paediatric nursing workforce.
\end{abstract}

S Afr J Child Health 2019;13(3):105-107. https://doi.org/10.7196/SAJCH.2019.v13i3.1556

Increasing the size and capacity of the specialist paediatric nursing workforce is advocated as a response to the pressing health needs of South Africa's (SA) large and growing child population, currently constituting $34 \%$ of the total population. ${ }^{[1]}$ Concern has been expressed regarding the size and composition of the current nursing workforce in general ${ }^{[2]}$ and the paediatric nursing workforce in particular. ${ }^{[3,4]}$ Most recently, Lala et al..$^{[5]}$ recommended that 'urgent interventions are required to resolve the nursing crisis in state hospital-based paediatric practice.'

The South African Nursing Council (SANC) defines a paediatric nurse as a nurse with in-depth knowledge and expertise in the specific practice area of paediatric nursing, and who holds a recognised postgraduate diploma yielding professional registration with SANC as a Nurse specialist: Paediatric nursing. ${ }^{[6]}$ Noting that all nursing education institutions (NEIs) are required to align paediatric nursing programmes with level 8 of the National Qualifications Framework (NQF) by 2019, we have extended this definition to include the unknown proportion of the paediatric nursing workforce currently qualified through post-basic education not yet aligned to this NQF level. NEIs maintain records, but do not routinely publish training output figures that indicate the number of paediatric nurses entering the workforce. Precise information also is not available from the published register maintained by SANC, with statutory records acknowledged by the national Department of Health seen as 'not a true reflection of the numbers of health professionals available for the workforce. ${ }^{[7]}$ There is a pressing need to establish an accurate depiction of the paediatric nursing workforce in SA to inform decisions regarding capacity building.

\section{Methods}

To improve the understanding regarding the capacity of the paediatric nursing workforce in SA, the study aimed to gather information about paediatric nursing training activity in SA. Objectives were to identify the extent of paediatric nursing training activity in relation to (i) graduate outputs for the period 2012 - 2016 and (ii) basic characteristics of the educational programmes offered. A descriptive empirical study was conducted, employing a structured questionnaire survey administered to key informants at NEIs currently registered with SANC as offering accredited postgraduate training. In the absence of a single authoritative source of information regarding paediatric nursing training activity, three sources were consulted to identify all NEIs producing paediatric nurses, namely: the Forum of University Nursing Deans of South Africa (FUNDISA) handbook; SANC's published records of NEIs offering accredited paediatric nursing training programmes; and the records of the South African Children's Nursing Educators Forum (CNEF). The latter is a forum established in 2015, providing peer support to nursing educators who contribute to paediatric nursing training programmes.

Eligible respondents had to hold a leadership role in a programme offered by an NEI recognised by SANC as yielding professional registration as a Nurse specialist: Paediatric nursing. A structured questionnaire was distributed electronically to respondents for selfcompletion. The questionnaire was designed pragmatically to elicit information that could contribute to an improved understanding of the paediatric nursing workforce and associated training activity in relation to: the number of institutions that provide training leading to qualification as a paediatric nurse; the number of paediatric nurses graduating annually over the last 5 years; and the description and NQF level of the relevant educational programmes at each institution. Information was requested for the period $2012-2016$.

Identified NEIs were approached by the researcher via email and telephonic communication to invite their participation. All institutions received written information about the study. All respondents provided written consent prior to their participation. Ethical approval for the study was obtained from the Human Research Ethics Committee at the Faculty of Health Sciences, University of Cape Town (ref. no. 717/2016). Data were analysed in spreadsheet format.

Of the seven NEIs approached, six agreed to participate in the study. For one of these, permission could not be secured in time and a total of five eventually participated. In view of the incomplete nature of the data set, data were subsequently supplemented with information obtained from the records of a CNEF meeting held in Cape Town in December 2016. This provided information for the 
preceding academic year (2015) for seven institutions, which allowed extrapolation of output figures for the two missing NEIs for the period 2012 - 2016, as described later.

\section{Results}

Data obtained from the survey, together with those from the CNEF records, are summarised in Table 1 .

\section{How many institutions provide training leading to qualification as a paediatric nurse?}

Findings confirmed that seven NEIs in SA provide training that leads to a registerable paediatric nursing specialisation. These include four colleges and three universities (Table 1). Respondents did not identify any additional institutions. The information extracted from the FUNDISA directory and the SANC list was confirmed by participants from the CNEF.

\section{How many paediatric nurses are being produced through the training programmes?}

A total of 637 paediatric nursing students from SA and other African countries were reported to have been enrolled at the five responding institutions between 2012 and 2016. Of the total complement, 545 were reported to have graduated, suggesting a programme completion rate of at least $85 \%$. Although institutions reported fluctuations in the number of students enrolled and graduating each year, year-on-year completion rates remained fairly stable.

Of the five participating NEIs, three reported training 60 paediatric nursing students from Southern African Development Community (SADC) countries other than SA. The majority of these (50/60) were trained by a single institution. The remaining 10 graduated from two other institutions during the same period. Respondents indicated that only one SA institution currently accepts trainees from SADC countries; the other NEIs suspended international admissions in recent years because of ongoing difficulties in securing temporary registrations for international students with the SANC.

Owing to the incomplete data set obtained through the questionnaire survey, information from the records of the CNEF was included to allow average training output figures to be calculated from the seven identified NEIs for the period of interest. We used the actual reported training output figures from five institutions for 2012 - 2016 and extrapolated output for the missing two institutions for the same period based on the complete data set for 2015 obtained from the CNEF. This yielded a figure of 765 paediatric nurses produced by seven NEIs between 2012 and 2016, which translates to a combined mean annual output of 153 paediatric nurses.

\section{What educational programmes are on offer?}

Ten educational programmes were identified, eight of which resulted in a qualification eligible for additional professional registration as a nurse specialist (paediatric nursing) with SANC (Table 1). These programmes correspond to NQF levels 6, 7 and 8, although revisions to the NQF architecture require all post-registration programmes to realign to NQF level 8 from 2019. The Master of Nursing in Child Nursing (MNCN) programme offered at the University of Cape Town since 2016 is accredited as a professional master's qualification at NQF Level 9 and prepares advanced clinical nursing practitioners. This qualification yields no professional registration, but can be logged as an additional qualification with SANC. Entrants to the MNCN programme need to already have an additional qualification as a nurse specialist: paediatric nursing.

\section{Discussion}

The empirically derived numbers of paediatric nurses trained determined in this study conflicts with those reported in the SA Human Resources for Health (HRH) strategy of 2011. ${ }^{[7]}$ To better understand the discrepancy, we reviewed the SANC records. The HRH strategy reflected only 1497 paediatric nursing specialists for 2010, which represents just more than half the 2772 reported in the 2010 annual SANC circular regarding additional qualifications on the register. The number reported in the HRH strategy corresponds perfectly with the number of nurses holding an additional qualification in paediatric nursing science recorded on the SANC register. However, this qualification is just one of five categories of additional qualification recognised nationally as conferring the status of nurse specialist: paediatric nursing. The total number of nurses with the qualification 'Paeds Nurs' as reflected in the HRH strategy therefore omits 1216 registrants recorded as holding additional qualifications in Post-Basic Child Nursing Science in 2010, and a

Table 1. Paediatric nursing training activity in South Africa

\begin{tabular}{|c|c|c|c|}
\hline Institution $^{*}$ & Programme title & NQF level & Duration of study \\
\hline Ga-Rankuwa Nursing College, Pretoria, Gauteng & Post Basic Diploma in Child Nursing Science ${ }^{\dagger}$ & 6 & 1 year \\
\hline $\begin{array}{l}\text { King Edward VIII School of Nursing, } \\
\text { Pietermaritzburg, KwaZulu-Natal }\end{array}$ & Post Graduate Diploma Child Nursing Science ${ }^{\dagger}$ & 6 & 1 year \\
\hline $\begin{array}{l}\text { Lilitha Nursing College, East London, Eastern } \\
\text { Cape }\end{array}$ & Post Basic Diploma in Child Nursing Science ${ }^{\dagger}$ & 6 & 1 year \\
\hline $\begin{array}{l}\text { Chris Hani Baragwanath Nursing College } \\
\text { (Rahima Moosa Campus), Johannesburg, Gauteng }\end{array}$ & Post Basic Diploma in Child Nursing Science ${ }^{\dagger}$ & 6 & 1 year \\
\hline \multirow[t]{3}{*}{ University of Cape Town, Western Cape } & Post Graduate Diploma in Child Nursing ${ }^{\dagger}$ & 8 & 1 year \\
\hline & Post Graduate Diploma in Child Critical Care Nursing ${ }^{\dagger}$ & 8 & 1 year \\
\hline & Master of Nursing in Child Nursing ${ }^{\ddagger}$ & 9 & 2 years \\
\hline $\begin{array}{l}\text { Department of Nursing Science, University of } \\
\text { Pretoria, Pretoria, Gauteng }\end{array}$ & $\begin{array}{l}\text { Bachelor of Nursing for Registered Nurses with } \\
\text { Children's Nursing Qualification }{ }^{\dagger}\end{array}$ & 7 & 1 year \\
\hline \multirow[t]{2}{*}{$\begin{array}{l}\text { School of Nursing, University of the Free State, } \\
\text { Bloemfontein, Free State }\end{array}$} & $\begin{array}{l}\text { Advanced Diploma in Nursing (Child Psychiatric } \\
\text { Nursing) }\end{array}$ & 7 & 1 year \\
\hline & Advanced Diploma in Nursing (Children's Nursing) ${ }^{\dagger}$ & 7 & 1 year \\
\hline \multicolumn{4}{|c|}{$\begin{array}{l}\mathrm{NQF}=\text { National Qualifications Framework. } \\
{ }^{*} \mathrm{~A} \text { post-basic education leading to a registerable qualification in paediatric nursing is also offered by the University of the Witwatersrand, but the programme was not of } \\
\text { during the period of data collection. } \\
{ }^{\dagger} \text { This qualification yields a professional registration as a Nurse specialist: Paediatric nursing with the South African Nursing Council (SANC). } \\
\text { †This qualification yields no professional registration, but can be logged as an additional qualification with SANC. Entrants to this programme need to already have an } \\
\text { additional qualification as a nurse specialist: paediatric nursing. First graduates were produced in } 2017 \text {. }\end{array}$} \\
\hline
\end{tabular}


further 59 registrants in either Advanced Paediatrics and Neonatal Nursing Science, Critical Care Nursing - Child or Paediatric Intensive Nursing. When all additional post-basic qualifications that confer the status of Nurse specialist: Paediatric nursing are considered, SANC's records show an increase of $12.3 \%$ in the number of paediatric nurses over six years, from 2772 in 2010 to 3115 in 2016 .

Although the HRH strategy presents a declining trend in the number of registrants holding an additional qualification in paediatric nursing science, which has been interpreted as representing a general decline in paediatric nursing training activity, ${ }^{[4]}$ our findings suggest growth.

There is a need for accurate official figures regarding the size of the specialist paediatric nursing workforce to provide a firm basis for human resource planning and capacity development. Developing accurate information systems to facilitate a more meticulous approach to generating coherent and synchronous information between national strategy and policy documents, training institutions, SANC and employers is recommended.

\section{Conclusion}

Although there is still a long way to go before staffing levels for paediatric units are optimised in SA health facilities, the findings of this limited assessment affirms that paediatric nurses are a key specialist resource in the SA healthcare system. Extrapolation from the data suggests that seven NEIs produced an estimated 765 paediatric nurses between 2012 and 2016.

With the ability of training programmes to potentially add an estimated 153 paediatric nurses to the SA nursing workforce each year, there is an urgent need to understand more about the deployment and utilisation of this important group of specialist nursing professionals, and to make that information available, to ensure safe, effective care for sick and injured children.
Declaration. This study was undertaken as part of a Master of Public Health mini dissertation.

Acknowledgements. The authors thank the respondents for completing the survey and Prof. M Coetzee for advice on study conceptualisation.

Author contributions. UU was the primary researcher and lead author of the study. NN and SS were co-supervisors to the study and contributed to data analysis and manuscript preparation. MSK was the study supervisor and contributed to manuscript preparation.

Funding. None.

Conflicts of interest. None.

1. Department of Health (DoH). Second triennial report of the Committee on Morbidity and Mortality in Children Under 5 Years. Pretoria: DoH, 2014.

2. Rispel L, Bruce J. A profession in peril? Revitalising nursing in South Africa. In: Padarath A, King J, English R, eds. South African Health Review 2014/15. Durban: Health Systems Trust, 2015.

3. McKerrow N. Training nurses to reduce child mortality. Curationis 2014;37(2):E1-2. https://doi.org/10.4102/curationis.v37i2.1475

4. Coetzee M. Re-envisioning paediatric nurse training in a re-engineered health care system. Curationis 2014;37:8. https://doi.org/10.4102/curationis. v37i2.1261

5. Lala SG, Lala N, Dangor Z. The nursing crisis in paediatrics in South African state hospitals - an unaddressed problem. S Afr J Child Health 2017;11(2):6465. https://doi.org/10.7196/sajch.2017.v11i2.1432

6. South African Nursing Council. Position Paper on Advanced Practice Nursing. 2012. http://www.sanc.co.za/position_advanced_practice_nursing.htm (accessed 24 April 2016).

7. Department of Health (DoH). HRH Strategy for the Health Sector: 2012/132016/17. Pretoria: DoH, 2011.

Accepted 12 December 2018. 